\title{
Development of a tool to measure the number of foods and beverages consumed by children using National Health and Nutrition Examination Survey (NHANES) FFQ data
}

\author{
Kelly J Tanner ${ }^{1, *}$ and Rosanna P Watowicz ${ }^{2}$ \\ 'Nationwide Children's Hospital, Division of Clinical Therapies, 700 Children's Drive, Columbus, OH 43205, USA: \\ ${ }^{2}$ Department of Nutrition, Case Western Reserve University, Cleveland, OH, USA
}

Submitted 19 July 2017: Final revision received 1 December 2017: Accepted 7 December 2017: First published online 1 February 2018

\begin{abstract}
Objective: There is currently no standard, objective definition of selective eating. This is partially because normative values for the number of different foods eaten by US children have not been established. The present study objectives were to: (i) perform exploratory analysis on the number of different foods, beverages, and total foods and beverages consumed by US children aged 2-18 years over a year's time, and the types of foods consumed by those in the lowest $2 \cdot 5$ th percentile; and (ii) determine whether those values differ according to demographic variables and weight status.

Design: Secondary analysis of cross-sectional FFQ data. Differences in number of foods, beverages, and total foods and beverages were analysed using oneway ANOVA.

Setting: National Health and Nutrition Examination Survey (NHANES) for the years 2003-2006.

Subjects: Non-institutionalized US children aged 2-18 years.

Results: The mean number of different foods and beverages consumed across the sample was $83 \cdot 2$. There were no significant differences by gender, BMI, race or food security categories. There was a difference in beverage consumption by age category, with children aged 12-18 years consuming a significantly higher number of different beverages compared with each of the other two age categories (i.e. 2-5 years and 6-11 years).

Conclusions: Normative values for the number of foods and drinks reported as consumed by children over the past 12 months may be a useful measure for researchers. Future research validating this measure is needed before cut-off values can be used to develop a definition of selective eating.
\end{abstract}

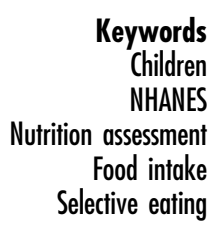

Selective eating (commonly known as 'picky eating') is a phenomenon that has been difficult to conceptualize. There are several reasons for this, including the fact that it is multifactored and exists on a continuum from developmentally appropriate 'pickiness' to an extremely limited diet of only a few foods. Recently, Bandini et al. have conceptualized selective eating as a combination of limited food acceptance and a high rate of food refusal ${ }^{(1)}$; in addition, it may be accompanied by food neophobia ${ }^{(2)}$. Many typically developing children experience selective eating, especially during toddlerhood ${ }^{(3)}$. While many children go on to eat a variety of foods, for others the problem persists through childhood and even into adulthood ${ }^{(4-6)}$. Parents of selective eaters may be concerned about their child's eating habits for several reasons. First, parents may be concerned about their child's intake of key nutrients. Although the results have been mixed, selective eating has been associated with lower diet variety and diversity scores ${ }^{(7)}$, nutrient inadequacies ${ }^{(1)}$ and liking fewer fruits and vegetables ${ }^{(8)}$. While eating fewer fruits and vegetables is associated with childhood overweight $^{(9)}$, parents may also have concerns about childhood underweight related to selective eating. However, parent concerns in some cases may be unfounded since there is evidence in the literature that parent-perceived picky eater status is not correlated with height, weight or nutrition status for children aged 42-84 months ${ }^{(4)}$. Selective eating may also be concerning for parents because it is often accompanied by more frequent challenging behaviours during mealtime ${ }^{(10)}$.

Despite the impact of selective eating on children and their families, research on selective eating has been difficult to undertake to date. One reason for this has been the 
aforementioned lack of a standard, objective definition of selective eating ${ }^{(2)}$. There are several different methods by which researchers and clinicians have attempted to operationalize the concept of selective eating in order to define groups for analysis. First, many studies have simply used parent perception (i.e. some version of the question 'Is your child a picky eater?') to divide children into groups $^{(3,11)}$. For this, researchers have used investigatordeveloped questions that specifically do not describe the term 'picky eater', in order to capture parental interpretation more purely. The significant limitation of this method is its inherent subjectivity (i.e. each parent's concept of 'picky eating' will be highly variable based on his/her own interpretation). While this may be a useful way to divide participants into groups for research that focuses on parent perspectives, it may not meet the needs of researchers who require a more objective measure of selective eating.

Others have used scores from various questionnaires to indicate relative 'pickiness' either by using investigatordetermined cut-off scores or by representing the concept on a continuum (i.e. the higher the score, the more selective the child $)^{(1,12,13)}$. Specifically, researchers have used variables derived from the Youth/Adolescent Questionnaire FFQ ${ }^{(14)}$ to plot children on a continuum of selectivity, which is useful for conducting research using statistical methods that do not require division into groups $^{(1)}$. Scores on the Child Feeding Questionnaire ${ }^{(15)}$ have been used to divide children into distinct groups of 'picky' $v$. 'non-picky', using a combination of items that was shown to have good internal consistency ${ }^{(12)}$. In another study, the authors selected a combination of items from the Food Neophobia Scale for Children and the Food Situations Questionnaire using principal components analysis, which yielded a cut-off score for picky eating ${ }^{(13)}$. Notably, the questionnaires used in the latter two studies still rely on parent report of selective eating behaviours, rather than analysing the number of foods eaten as in the Bandini et al. study ${ }^{(1)}$.

Finally, anecdotal definitions of selective eating based on number of foods eaten by the child are commonly used in clinical settings (i.e. a child who eats 'twenty foods or less' may be considered a selective eater) ${ }^{(15)}$. While clinical judgement is certainly an important component of determining whether treatment is warranted, these definitions are not accompanied by standardized methods and tools for data collection and have not been validated through research. Thus, a standard, objective definition of selective eating continues to elude the field.

The development of a tool to objectively define selective eating would have important implications for researchers in the field. Researchers may find that it is easier to assign participants to groups for both descriptive and intervention research or to determine whether their study sample is representative of the population. In addition, normative data may lead to a standardized definition of selective eating, which would make it easier to share data among researchers, replicate study findings and compare study findings between research groups. If such a tool were later validated for clinical applications, clinicians would potentially find a streamlined assessment process, although input from multiple professionals is still considered best practice. The objective assessment could be used alongside parental concerns regarding the child's eating habits and growth trajectory to determine whether a child's food intake is of clinical concern.

By developing a tool to determine the number of foods and beverages that children consume in comparison to a national sample, we may begin to explore food and beverage consumption patterns that represent a potential aberration from the norm and therefore a potential concern. The objectives of the present project were to: (i) perform exploratory analysis on the number of different foods and beverages US children aged 2-18 years consume over a year's time, and the types of foods consumed by those in the lowest percentiles; and (ii) determine whether these values differ systematically according to demographic (i.e. age, gender, race/ethnicity, food security) variables or weight status. Because our first research question was exploratory in nature, we did not generate specific hypotheses. For our second research question, we hypothesized that there would be systematic differences based on demographic and body measurement variables. Specifically, we hypothesized that children who were younger and over- or underweight would eat fewer different foods.

\section{Methods}

The current study was a cross-sectional examination of the number of foods and beverages consumed by US children aged 2-18 years. Dietary, demographic, body measure and food security data from the National Health and Nutrition Examination Survey (NHANES) were used for analysis. The research used de-identified data and, therefore, did not require approval by an institutional review board.

\section{NHANES FFO}

NHANES is a nationally representative survey of the US population conducted by the National Center for Health Statistics and the Centers for Disease Control and Prevention. The purpose of the survey is to measure the health and nutritional status of non-institutionalized individuals in the USA; it has run in continuous two-year cycles since 1999. In the 2003-2004 and 2005-2006 survey cycles, an FFQ was collected as part of the dietary data for individuals 2 years of age or older. We chose to use the NHANES FFQ for the present study instead of the NHANES $24 \mathrm{~h}$ recall data to capture intake of foods that are consumed episodically. While $24 \mathrm{~h}$ recalls are far better at capturing absolute intakes of foods and nutrients, the purpose of our study was to examine the variety of foods 
consumed. The NHANES FFQ and our secondary analysis herein are not intended to accurately assess portion size or nutrient intake ${ }^{(16)}$.

The NHANES FFQ assessed the frequency of intake of 152 foods or food categories over the past 12 months. The NHANES FFQ was developed by the National Cancer Institute and was based on the National Cancer Institute's Diet History Questionnaire ${ }^{(17,18)}$. The list of foods used for the original Diet History Questionnaire was generated using adult $24 \mathrm{~h}$ recall data collected via the 1994-1996 Continuing Survey of Food Intakes by Individuals (CSFII), a national food consumption survey conducted by the US Department of Agriculture. In developing the NHANES FFQ, child data from the 1994-1996 and 1998 CSFII were analysed to explore whether additional foods should be included. As a result of this analysis, questions on apple juice, grape juice, granola bar and pudding/custard consumption were added ${ }^{(19)}$. The NHANES FFQ includes questions on food sources of nutrients of concern for children, including $\mathrm{Ca}$, vitamin $\mathrm{D}, \mathrm{K}$ and fibre (e.g. milk, yoghurt, fruits and vegetables) ${ }^{(20)}$.

For the current study, we examined the FFQ data for children 2-18 years old. Responses were either selfreported (for children 12 years of age or older), proxyassisted (children 6-11 years of age) or proxy-reported (children under 6 years of age).

\section{Preparing the $F F Q$ data}

For the present study, we used the 'FFQ - Output from DietCalc Software' file from the 2003-2004 and 2005-2006 NHANES dietary data (available at http://www.nhanes. org). The authors reviewed the list of 152 foods/food categories (variable FFQ_VAR in the data file) to identify any foods/food categories that should be combined or excluded. For example, food categories that were too broad, such as 'other fruits' and 'other vegetables', were excluded for the present study's purposes because we could not discern the number of different foods the child ate within each of those categories. Additionally, certain foods that are typically only consumed as additives (such as cream or sugar added to beverages) were also excluded. Finally, food categories that measured seasonal consumption were combined across seasons (for example, 'corn - in season' and 'corn - rest of year' were combined to assess whether corn was consumed at all during the 12-month period). Each of the foods and beverages on the final list of 122 foods/food categories were coded as 'food' or 'beverage' based on author review, resulting in 106 foods and sixteen beverages. The final recoded categories used for analysis can be found in Table 1.

While the NHANES FFQ does attempt to capture frequency of intake (for example, 2-3 times per month, 5-6 times per week, etc.), mentally calculating average intake over time can be challenging, particularly for children. Since this cognitive challenge can introduce bias, and because average frequency of consumption was not

Table 1 List of foods and beverages included in the analysis, recoded from the National Health and Nutrition Examination Survey (NHANES) FFQ

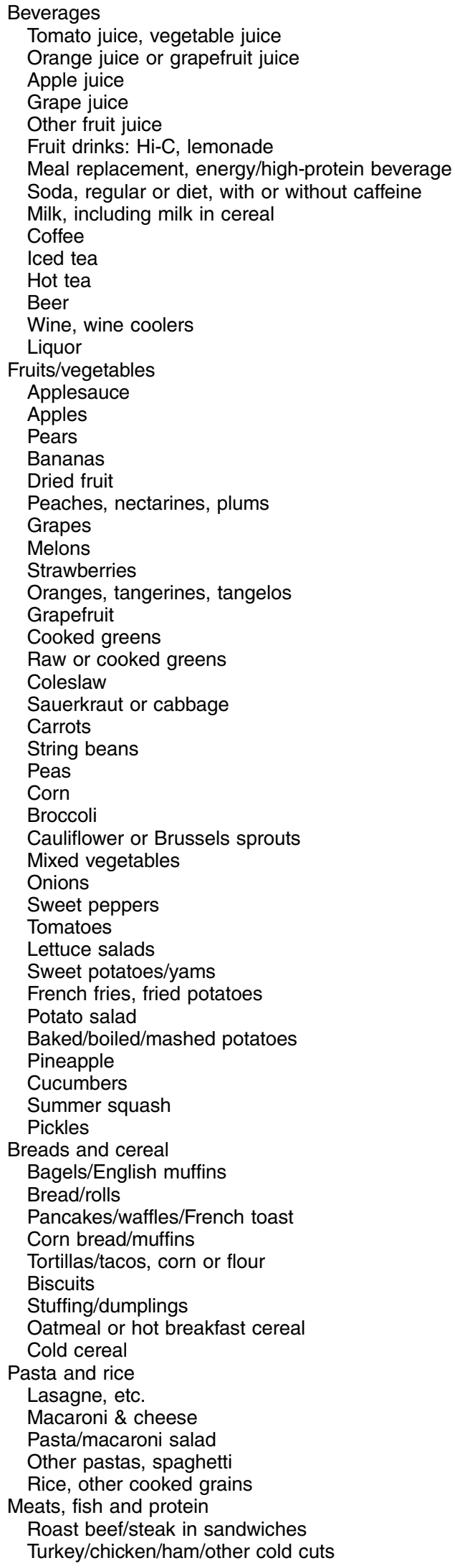


Table 1 Continued

\begin{tabular}{l} 
Tuna \\
Ground chicken/turkey \\
Beef hamburgers/cheeseburgers \\
Ground beef in mixtures \\
Hot dogs \\
Beef stew/pot pie \& veg \\
Roast beef/pot roast \\
Steak \\
Pork/beef spareribs \\
Roast turkey \\
Chicken, including in salads/mixtures \\
Baked ham/ham steak \\
Pork \\
Liver/liverwurst \\
Bacon \\
Sausage \\
Fried fish/fish sticks \\
Fish, not fried, smoked, raw \\
Smoked fish/seafood \\
Sushi \\
Raw oysters/clams \\
Tofu, soya burgers/soya meat substitute \\
Eggs, including in salad \\
Dried, cooked beans \\
Dairy foods \\
Yoghurt \\
Cottage cheese \\
Cheese \\
Mixed dishes \\
Chilli \\
Soup \\
Pizza \\
Snack foods \\
Crackers \\
Potato chips \\
Popcorn \\
Pretzels \\
Peanuts/walnuts/seeds/other nuts \\
Granola bars \\
Tortilla/corn chips \\
Dessert foods \\
Frozen yoghurt, ices/sorbet, ice cream/ice-cream bars/sherbet \\
Pudding/custard \\
Cake \\
Brownies/cookies \\
Doughnuts/sweet rolls/Danish/pop tarts \\
Sweet muffins/dessert breads \\
Fruit crisp/cobbler/pies \\
Chocolate candy \\
Other candy \\
Condiments \\
Salsa \\
Ketchup \\
Jam/jelly/honey \\
Peanut butter/other nut butter \\
Gravy \\
Margarine on breads/pancakes or potatoes/vegetables \\
Butter on breads/pancakes or potatoes/vegetables \\
Mayonnaise \\
Cream cheese \\
Sour cream \\
Salad dressing \\
Oils for cooking \\
\hline
\end{tabular}

important for the purposes of the present study, frequency data were recoded. Response options on the NHANES FFQ were categorical, ranging from 'never' to 'six or more times per day'. Responses for each food/food category were recoded into a dichotomous variable ('never' $=$ not consumed; anything greater than 'never' = consumed) to assess whether the child had consumed the food/food category at all over the past 12 months.

\section{Additional NHANES data}

Age, gender, race/ethnicity, measured height, measured weight and BMI data from the demographic and body measures components of NHANES were merged into the data file for analysis. Age was recoded into a categorical variable (2-5 years, 6-11 years, 12-18 years). Age- and sex-specific BMI percentile was calculated for each participant based on measured height and weight, and individuals were categorized as underweight ( $<5$ th percentile), normal weight ( 5 th to $<85$ th percentile), overweight ( 85 th to $<95$ th percentile) or obese ( 95 th percentile or above) in accordance with Centers for Disease Control and Prevention guidelines. Finally, household food security category was merged into the data file. Participants were considered to be in one of four household food security categories (full food security, marginal food security, low food security, very low food security) based on adult responses to the eighteen-item US Household Food Security Module ${ }^{(21)}$, which is collected as part of the NHANES Food Security questionnaire.

\section{Analysis}

All analyses were conducted using complex samples and weighted data. NHANES data are weighted to provide an accurate demographic representation of the national population given that the survey oversamples certain groups within the population ${ }^{(22)}$. Per NHANES analysis guidelines, the two-year FFQ sample weights, provided as part of the NHANES FFQ raw data for each data cycle, were divided by 2 to calculate the four-year FFQ sample weights $^{(23)}$. Complex sampling analysis is recommended for NHANES data to accurately calculate estimates of variability (i.e. standard error of the mean) based on the number of individuals in the sample rather than the number of individuals in the population or weighted sample. Because of the extremely large size of the weighted sample, estimates of variability based on the number of individuals in the weighted sample would be artificially low. For the current study, a complex sampling plan was built per NHANES analysis guidelines ${ }^{(23)}$, using the stratum variable (SDMVSTRA) and cluster variable (SDMVPSU) provided in the NHANES demographic data file, as well as the calculated four-year FFQ sample weight. Individuals with ten or more missing FFQ responses were excluded from analysis.

Descriptive and frequency analyses were used to determine the characteristics of the sample. Descriptive statistics were used to determine the mean number of foods, beverages, and total foods and beverages for the sample and sub-categories within the sample. Descriptive statistics were also used to estimate the number of foods and beverages 
consumed at various percentiles across the population. Frequency analysis was used to examine the types of foods consumed by the children in the lowest $2 \cdot 5$ th percentile for total number of foods and beverages consumed.

One-way ANOVA was used to test for differences in number of foods, beverages, and total number of foods and beverages across gender, age, race, BMI and food security categories. A conservative significance level of 0.01 was used to reduce the risk of type 1 error due to the multiple comparisons. The Bonferroni method was used for post hoc testing where the overall significance level was equal to or less than $0 \cdot 01$.

Except for the BMI percentile data, which were calculated using the SAS program provided by the Centers for Disease Control (available at http://www.cdc. gov/nccdphp/dnpao/growthcharts/resources/sas.htm), all analyses were conducted using the statistical software package IBM SPSS Statistics for Windows version 24.0.

\section{Results}

After excluding 325 subjects missing ten or more FFQ responses, 4952 children were included in the final sample, representing over 69 million US children. Demographic characteristics of the weighted sample can be found in Table 2 .

US children consumed an average of 83.2 different foods and beverages over the previous 12 months. The mean number of foods and beverages consumed by the

Table 2 Characteristics of the sample of children aged 2-18 years, weighted data from National Health and Nutrition Examination Survey (NHANES) 2003-2006

\begin{tabular}{|c|c|c|}
\hline & $\%$ & SE \\
\hline \multicolumn{3}{|l|}{ Sex } \\
\hline Male & 50.5 & 1.2 \\
\hline Female & 49.5 & 1.2 \\
\hline \multicolumn{3}{|l|}{ Age } \\
\hline $2-5$ years & $22 \cdot 2$ & 0.9 \\
\hline $6-11$ years & 34.7 & 1.0 \\
\hline $12-18$ years & $43 \cdot 1$ & 1.6 \\
\hline \multicolumn{3}{|l|}{ BMI category* } \\
\hline Underweight & $3 \cdot 3$ & 0.4 \\
\hline Normal weight & 65.3 & 1.9 \\
\hline Overweight & $15 \cdot 8$ & $1 \cdot 2$ \\
\hline Obese & $15 \cdot 7$ & 1.2 \\
\hline \multicolumn{3}{|l|}{ Race/ethnicity } \\
\hline Mexican American & $13 \cdot 1$ & 1.5 \\
\hline Other Hispanic & $3 \cdot 1$ & 0.5 \\
\hline White & $62 \cdot 6$ & 3.1 \\
\hline Black & 14.9 & 1.9 \\
\hline Other, including multi-racial & $6 \cdot 3$ & 1.0 \\
\hline \multicolumn{3}{|l|}{ Household food security status } \\
\hline Full food security & 75.4 & 1.6 \\
\hline Marginal food security & $7 \cdot 3$ & 0.6 \\
\hline Low food security & $11 \cdot 0$ & 0.9 \\
\hline Very low food security & $6 \cdot 3$ & 0.8 \\
\hline
\end{tabular}

*BMI percentiles were categorized based on guidelines from the Centers for Disease Control and Prevention: underweight $(<5$ th percentile), normal weight (5th to $<85$ th percentile), overweight (85th to $<95$ th percentile) and obese ( $\geq 95$ th percentile) total sample and for each demographic group can be found in Table 3. There were no significant differences by gender, BMI, race or food security categories. Children in the 12-18 years age category consumed a significantly higher number of different beverages compared with each of the other two age categories; however, there was no difference in number of foods consumed or total number of foods and beverages consumed.

The number of foods and beverages consumed at selected percentiles across the population is listed in Table 4.

Analysis showing the top foods consumed by children in the bottom $2 \cdot 5$ th percentile ( 127 children in the unweighted sample) can be found in Table 5. These top foods were largely carbohydrate-based, energy-dense foods. The top non-potato vegetable reported by this sub-sample of children was corn ( $n$ 55) and the top non-starchy vegetable consumed by this sub-sample was carrots ( $n$ 52). There were no non-potato vegetables reported by at least half of the sub-sample as being consumed in the last year.

\section{Discussion}

With regard to our first objective, we found that the mean number of total foods and beverages consumed by children in the US over the past 12 months was 83.2, while the 2.5 th percentile was $43 \cdot 0$. These data provide reference values to help researchers objectively assess where a child falls on the continuum of food and beverage variety. It should be noted that these reference values apply when using the same list of foods and beverages included in the NHANES data set, which we analysed in the present study (see Table 1). Additional research regarding the use of this FFQ for research is needed to determine its reliability and responsivity; however, initial information on its validity can be gleaned from the list of top foods consumed by children in the $2 \cdot 5$ th percentile (see Table 4 ).

Our hypothesis for our second objective was, for the most part, not supported (except for beverages for children aged 12-18 years). This finding was surprising for several reasons. First, previous research has suggested that there is an effect of age on selective eating ${ }^{(2,24)}$. However, other research has suggested that while selective eating may decrease on average with child age, there may be a subset of children for whom the problem persists even into adulthood ${ }^{(4,12)}$. The present study did show a positive relationship between age and beverage consumption for children 12-18 years old, but not for foods or total foods and beverages.

Research on the relationship between picky eating and weight status in children is largely inconclusive. Certain studies have shown that children of pre-school age with obesity are more picky than normal-weight children ${ }^{(25)}$, and that picky eaters have a higher intake of savoury snacks and sweets (risk factors for obesity) at age 
Table 3 Mean number of foods and beverages reported as consumed in the last 12 months by children aged 2-18 years: National Health and Nutrition Examination Survey (NHANES) 2003-2006

\begin{tabular}{|c|c|c|c|c|c|c|}
\hline & \multicolumn{2}{|c|}{$\begin{array}{l}\text { Number of foods } \\
\text { consumed }\end{array}$} & \multicolumn{2}{|c|}{$\begin{array}{c}\text { Number of beverages } \\
\text { consumed }\end{array}$} & \multicolumn{2}{|c|}{$\begin{array}{c}\text { Total number of foods and beverages } \\
\text { consumed }\end{array}$} \\
\hline & Mean & SE & Mean & SE & Mean & SE \\
\hline Total sample & $75 \cdot 6$ & 0.60 & $7 \cdot 5$ & 0.07 & 83.2 & 0.65 \\
\hline \multicolumn{7}{|l|}{ Sex } \\
\hline Male & $75 \cdot 3$ & 0.76 & 7.5 & 0.08 & $82 \cdot 8$ & 0.80 \\
\hline Female & $75 \cdot 9$ & 0.80 & 7.6 & 0.10 & 83.5 & 0.86 \\
\hline$P$ value* & 0.576 & & 0.236 & & 0.509 & \\
\hline \multicolumn{7}{|l|}{ Age } \\
\hline $2-5$ years & 74.9 & 0.68 & $7 \cdot 0^{\mathrm{a}}$ & 0.09 & $82 \cdot 0$ & 0.71 \\
\hline $6-11$ years & $76 \cdot 7$ & $1 \cdot 17$ & $7 \cdot 2^{\mathrm{a}}$ & 0.11 & 84.0 & 1.26 \\
\hline $12-18$ years & $75 \cdot 1$ & 0.58 & $8 \cdot 1^{\mathrm{b}}$ & 0.09 & 83.2 & 0.64 \\
\hline$P$ value* & 0.255 & & $<0.001$ & & 0.171 & \\
\hline \multicolumn{7}{|l|}{ BMI category $\dagger$} \\
\hline Underweight & $77 \cdot 0$ & 1.53 & 7.5 & 0.33 & 84.5 & 1.64 \\
\hline Normal weight & $76 \cdot 2$ & 0.76 & 7.5 & 0.08 & 83.8 & 0.80 \\
\hline Overweight & $75 \cdot 0$ & 0.79 & $7 \cdot 7$ & 0.10 & $82 \cdot 7$ & 0.84 \\
\hline Obese & $73 \cdot 7$ & 0.71 & 7.5 & 0.10 & $81 \cdot 2$ & 0.77 \\
\hline$P$ value* & 0.087 & & 0.306 & & 0.112 & \\
\hline \multicolumn{7}{|l|}{ Race/ethnicity } \\
\hline Mexican American & 75.9 & 0.87 & $7 \cdot 8$ & 0.08 & 83.7 & 0.94 \\
\hline Other Hispanic & $72 \cdot 0$ & 2.44 & $8 \cdot 1$ & 0.37 & $80 \cdot 0$ & 2.67 \\
\hline White & $75 \cdot 9$ & 0.92 & 7.4 & 0.10 & $83 \cdot 3$ & 0.98 \\
\hline Black & $75 \cdot 1$ & 0.78 & $7 \cdot 8$ & 0.07 & 82.9 & 0.83 \\
\hline Other including multi-racial & $75 \cdot 6$ & 1.73 & 7.5 & 0.17 & 83.1 & 1.87 \\
\hline$P$ value* & 0.652 & & 0.019 & & 0.779 & \\
\hline \multicolumn{7}{|l|}{ Household food security status } \\
\hline Full food security & $75 \cdot 2$ & 0.65 & 7.5 & 0.08 & $82 \cdot 6$ & 0.70 \\
\hline Marginal food security & $77 \cdot 3$ & 1.63 & 7.6 & 0.12 & 84.9 & 1.67 \\
\hline Low food security & $77 \cdot 3$ & 1.93 & $7 \cdot 8$ & 0.16 & $85 \cdot 1$ & 2.06 \\
\hline Very low food security & 76.4 & 1.47 & 8.0 & 0.26 & 84.5 & 1.66 \\
\hline$P$ value* & 0.197 & & 0.066 & & 0.135 & \\
\hline
\end{tabular}

a,b Mean values with unlike superscript letters were significantly different based on post hoc testing using the Bonferroni method $(P<0.01)$.

*Overall $P$ value across both/all categories.

†BMI percentiles were categorized based on guidelines from the Centers for Disease Control and Prevention: underweight $(<5$ th percentile), normal weight $(5$ th to $<85$ th percentile), overweight ( 85 th to $<95$ th percentile) and obese ( $\geq 95$ th percentile).

Table 4 Percentiles for number of foods and beverages consumed by children aged $2-18$ years: National Health and Nutrition Examination Survey (NHANES) 2003-2006

\begin{tabular}{lccc}
\hline Percentile & $\begin{array}{c}\text { Total number of foods } \\
\text { and beverages } \\
\text { consumed }\end{array}$ & $\begin{array}{c}\text { Number of } \\
\text { beverages } \\
\text { consumed }\end{array}$ & $\begin{array}{c}\text { Number of } \\
\text { foods } \\
\text { consumed }\end{array}$ \\
\hline 2.5th & 43 & 4 & 37 \\
5th & 50 & 4 & 44 \\
25th & 73 & 6 & 66 \\
50th & 86 & 7 & 78 \\
75th & 96 & 9 & 88 \\
95th & 107 & 11 & 98 \\
97.5th & 110 & 12 & 101 \\
\hline
\end{tabular}

14 months $^{(26)}$. However, other studies have shown a relationship between picky eating and underweight status $^{(12,27)}$. A systematic review of forty-one studies examining the relationship between picky eating and weight found that the evidence is conflicting, and this may be partially due to the inconsistencies in the measurement of picky eating ${ }^{(28)}$. The present study did not show a relationship between the intake of fewer foods/beverages and weight status.
Table 5 Top foods reported as consumed in the past 12 months by the subset of children aged $2-18$ years $(n 127)$ in the bottom $2 \cdot 5$ th percentile of total number of foods and beverages consumed: National Health and Nutrition Examination Survey (NHANES) 2003-2006

\begin{tabular}{lc}
\hline & Consumed $(n)$ \\
\hline Milk, including on cereal & 103 \\
French fries, fried potatoes & 102 \\
Orange juice or grapefruit juice & 99 \\
Pizza & 99 \\
Soda & 99 \\
Other candy & 89 \\
Apples & 85 \\
Ice cream/ice-cream bars/sherbet & 85 \\
Potato chips & 85 \\
Cold cereal & 84 \\
\hline
\end{tabular}

Although the aims of the present study were largely descriptive, future validation studies examining the relationship between the number of foods and beverages consumed and diet quality could provide additional insight as to whether the number of foods/beverages consumed is a valid and clinically meaningful measure of selective eating associated with adverse outcomes. For 
example, this measure could be validated by comparing the number of foods/beverages consumed with diet quality as measured by Healthy Eating Index score, which has been shown to be negatively associated with selective eating using other measures ${ }^{(29,30)}$. Others have shown that picky eating is inversely related to diet variety and fruit and vegetable consumption ${ }^{(31-34)}$. Our analysis of the top foods consumed by children in the lowest percentiles of number of foods and beverages consumed (Table 5) provides support for these previous studies. Our results show that the foods most commonly consumed by the bottom $2.5 \%$ of children are largely high-carbohydrate, energy-dense foods, with very few fruits and vegetables, indicating a low diet quality.

The measure used in the present study could also be validated against other measures of picky eating, such as parental report, in order to measure agreement. Jacobi et al. found that parent-reported pickiness was associated with a lower number and variety of foods eaten during a standardized home feeding ${ }^{(34)}$. Single-item parental report of picky eating has been used in several previous studies $^{(3,35-38)}$ and is particularly useful in a clinical setting where time is limited. If parental report of picky eating could be shown to correlate with normative population estimates of the number of foods and beverages consumed, clinicians may feel more comfortable using these single-item measures to assess picky eating.

We used data from the NHANES FFQ for the current study and propose that this would be a useful tool for researchers who require a more objective measure of selective eating than a single-item parent report. Additional research is needed to determine whether results would be similar using other long-form FFQ developed for and validated using a US sample (e.g. the Youth/Adolescent Questionnaire $)^{(14)}$. If this tool is to be used clinically then future studies should compare the results of the present study with results obtained using FFQ that are typically used clinically to examine how reliable the results are across measures.

The present study has several limitations. First, there is some concern around the cognitive challenge that an FFQ presents for children, especially given that, to our knowledge, neither the NHANES FFQ nor the National Cancer Institute FFQ that it is based upon has been validated in a paediatric population. A review of the reliability and validity of child/adolescent FFQ found a wide range of agreement between the various FFQ and the reference measures, ranging from weak to strong ${ }^{(39)}$. However, that review found that FFQ that do not assess portion size (like the NHANES FFQ) correlate better with the reference criterion than those that do assess portion size. This finding is supported by a cognitive interviewing study of adults conducted during the development of the NHANES FFQ, which found that cognitive issues were predominantly related to the reporting of portion size and the reporting of frequency in an open-ended fashion (i.e. '__ times per week' $v$. categories of ' $1-2$ times per week' ${ }^{(40)}$. For the current study, we were concerned only about the question of 'ever $v$. never consumed' as opposed to questions of frequency of consumption or portion size. There is a scarcity of literature examining the validity of 'ever $v$. never' FFQ, particularly in children. One study of adults, conducted during the development of the NHANES FFQ, showed that participants had high agreement (85-100\%) between the FFQ and $30 \mathrm{~d}$ of daily food reporting for specific foods that were examined ${ }^{(41)}$. Given this body of literature, we expect that our examination of 'ever $v$. never consumed' instead of specific nutrient intakes lessens the concerns around validity and cognitive challenges for children completing the NHANES FFQ.

Second, since the FFQ was proxy-assisted or proxyreported for many of the children surveyed, there is a chance that the responses were not completely accurate, as a parent may not be aware of every food and beverage consumed by the child. FFQ also inherently depend on memory, which may affect the accuracy of the report, particularly when asking about a 12-month period. However, the ability to accurately recall foods and beverages consumed should not be systematically different across varying demographic groups. Additionally, there is evidence that children who are overweight or obese systematically under-report energy intake when dietary intake is assessed ${ }^{(42-44)}$. However, it is unclear in the literature whether this is due to under-reporting of portion size, under-reporting of foods consumed, or both. If this is due to under-reporting of the number of foods consumed, then the norms presented herein may not be valid for children for children who are overweight and obese. We also acknowledge that the dietary data examined for the present study were collected more than a decade ago and eating patterns for children may not have been static over that time. However, we used the most recent nationally representative FFQ data available. Some children may have consumed foods or beverages that were not asked about on the FFQ and, therefore, their food and beverage counts may be artificially low. This may be of particular concern for children who do not eat a traditional American diet, as the NHANES FFQ includes very few foods consumed by individuals adhering to a traditional diet from another culture. Finally, the NHANES FFQ cannot differentiate between foods that were not offered to the child and foods that were offered but refused. It is possible that some children with low food/ beverage counts are not selective eaters, but rather are offered only a limited number of foods. However, the lack of a significant difference in number of foods/beverages consumed across demographic categories makes it unlikely that fewer foods are systematically being offered to any particular group (for example, low food security status, younger age). 


\section{Conclusion}

In conclusion, the normative values for the number of foods and drinks reported as consumed by children over the past 12 months may be a useful measure for both researchers and clinicians. Future research validating this measure is needed before cut-off values can be used to categorize a child as a selective eater.

\section{Acknowledgements}

Financial support: This research received no specific grant from any funding agency in the public, commercial or not-for-profit sectors. Conflict of interest: None. Authorship: K.J.T. conceptualized the research topic, performed the literature review, and wrote the first draft of the introduction and discussion sections. R.P.W. performed the data analysis and wrote the first draft of the methods and results sections. Both authors reviewed and revised subsequent drafts of the manuscript. Ethics of buman subject participation: Not applicable.

\section{References}

1. Bandini LG, Anderson SE, Curtin C et al. (2010) Food selectivity in children with autism spectrum disorders and typically developing children. J Pediatr 157, 259-264.

2. Dovey TM, Staples PA, Gibson EL et al. (2008) Food neophobia and 'picky/fussy' eating in children: a review. Appetite 50, 181-193.

3. Carruth BR, Ziegler PJ, Gordon A et al. (2004) Prevalence of picky eaters among infants and toddlers and their caregivers' decisions about offering a new food. J Am Diet Assoc 104, 57-64.

4. Carruth BR \& Skinner JD (2000) Revisiting the picky eater phenomenon: neophobic behaviors of young children. $J \mathrm{Am}$ Coll Nutr 19, 771-780.

5. Kauer J, Pelchat ML, Rozin P et al. (2015) Adult picky eating. Phenomenology, taste sensitivity, and psychological correlates. Appetite 90, 219-228.

6. Nicholls D, Christie D, Randall L et al. (2001) Selective eating: symptom, disorder or normal variant. Clin Child Psychol Psychiatry 6, 257-270.

7. Carruth BR, Skinner J, Houck K et al. (1998) The phenomenon of 'picky eater': a behavioral marker in eating patterns of toddlers. J Am Coll Nutr 17, 180-186.

8. Howard AJ, Mallan KM, Byrne R et al. (2012) Toddlers' food preferences. The impact of novel food exposure, maternal preferences and food neophobia. Appetite 59, 818-825.

9. Academy of Nutrition and Dietetics (2006) Evidence Summary: Fruit and Vegetable Intake and Childhood Overweight. http://www.andeal.org/topic.cfm?menu=5296\&pcat $=4156 \&$ cat $=4157$ (accessed October 2017).

10. Crist W \& Napier-Phillips ABA (2001) Mealtime behaviors of young children: a comparison of normative and clinical data. J Dev Behav Pediatr 22, 279-286.

11. Lockner DW, Crowe TK \& Skipper BJ (2008) Dietary intake and parents' perception of mealtime behaviors in preschoolage children with autism spectrum disorder and in typically developing children. J Am Diet Assoc 108, 1360-1363.

12. Berger PK, Hohman EE, Marini ME et al. (2016) Girls' picky eating in childhood is associated with normal weight status from ages 5 to 15 y. Am J Clin Nutr 104, 1577-1582.
13. Galloway AT, Lee Y \& Birch LL (2003) Predictors and consequences of food neophobia and pickiness in young girls. J Am Diet Assoc 103, 692-698.

14. Rockett HRH, Wolf AM \& Colditz GA (1995) Development and reproducibility of a food frequency questionnaire to assess diets of older children and adolescents. J Am Diet Assoc 95, 336-340.

15. Birch LL, Fisher JO, Grimm-Thomas K et al. (2001) Confirmatory factor analysis of the child feeding questionnaire: a measure of parental attitudes, beliefs and practices about child feeding and obesity proneness. Appetite 36, 201-210.

16. Toomey KA (2010) Picky Eaters vs. Problem Feeders I SOS Approach to Feeding. http://sosapproach-conferences. com/resources/picky-eaters-vs-problem-feeders/ (accessed January 2018).

17. National Center for Health Statistics (2008) NHANES 2003-2004: Food Frequency Questionnaire. https://wwwn. cdc.gov/Nchs/Nhanes/2003-2004/FFQDC_C.htm (accessed January 2018).

18. Subar AF, Thompson FE, Kipnis V et al. (2001) Comparative validation of the Block, Willett, and National Cancer Institute food frequency questionnaires: the Eating at America's Table study. Am J Epidemiol 154, 1089-1099.

19. National Center for Health Statistics (2008) NHANES 20052006: Food Frequency Questionnaire - Raw Questionnaire Responses Data Documentation, Codebook, and Frequencies. https://wwwn.cdc.gov/nchs/nhanes/2005-2006/FFQRAW_D. htm (accessed January 2018).

20. Ogata BN \& Hayes D (2014) Position of the Academy of Nutrition and Dietetics: nutrition guidance for healthy children ages 2 to 11 years. J Acad Nutr Diet 114, 1257-1276.

21. US Department of Agriculture, Economic Research Service (2012) USDA ERS Survey Tools: US Household Food Security Survey Module. http://www.ers.usda.gov/topics/ food-nutrition-assistance/food-security-in-the-us/surveytools/\#household (accessed January 2017).

22. Saylor J, Friedmann E \& Lee HJ (2012) Navigating complex sample analysis using national survey data. Nurs Res $\mathbf{6 1}$, 231-237.

23. Johnson CL, Paulose-Ram R, Ogden CL et al. (2013) National health and nutrition examination survey: analytic guidelines, 1999-2010. Vital Health Stat 2 issue 161, 1-24.

24. Nicklaus S, Boggio V, Chabanet C et al. (2005) A prospective study of food variety seeking in childhood, adolescence and early adult life. Appetite 44, 289-297.

25. Finistrella V, Manco M, Ferrara A et al. (2012) Crosssectional exploration of maternal reports of food neophobia and pickiness in preschooler-mother dyads. J Am Coll Nutr 31, 152-159.

26. Tharner A, Jansen PW, Kiefte-de Jong JC et al. (2014) Toward an operative diagnosis of fussy/picky eating: a latent profile approach in a population-based cohort. Int J Behav Nutr Phys Act 11, 14.

27. Jansen PW, Roza SJ, Jaddoe VW et al. (2012) Children's eating behavior, feeding practices of parents and weight problems in early childhood: results from the populationbased Generation R Study. Int J Behav Nutr Phys Act 9, 130.

28. Brown CL, Vander Schaaf EB, Cohen GM et al. (2016) Association of picky eating and food neophobia with weight: a systematic review. Child Obes 12, 247-262.

29. Falciglia GA, Couch SC, Gribble LS et al. (2000) Food neophobia in childhood affects dietary variety. J Am Diet Assoc 100, 1474-1481.

30. Quick V, Lipsky LM, Laffel LMB et al. (2014) Relationships of neophobia and pickiness with dietary variety, dietary quality and diabetes management adherence in youth with type 1 diabetes. Eur J Clin Nutr 68, 131-136.

31. Cooke L, Carnell S \& Wardle J (2006) Food neophobia and mealtime food consumption in 4-5 year old children. Int $J$ Behav Nutr Phys Act 3, 14. 
32. Galloway AT, Fiorito L, Lee Y et al. (2005) Parental pressure, dietary patterns, and weight status among girls who are 'picky eaters'. J Am Diet Assoc 105, 541-548.

33. Haszard JJ, Skidmore PML, Williams SM et al. (2015) Associations between parental feeding practices, problem food behaviours and dietary intake in New Zealand overweight children aged 4-8 years. Public Health Nutr 18, 1036-1043.

34. Jacobi C, Agras WS, Bryson S et al. (2003) Behavioral validation, precursors, and concomitants of picky eating in childhood. J Am Acad Child Adolesc Psychiatry 42, 76-84.

35. Northstone K \& Emmett P (2013) The associations between feeding difficulties and behaviours and dietary patterns at 2 years of age: the ALSPAC cohort. Matern Child Nutr $\mathbf{9}$, $533-542$.

36. Orün E, Erdil Z, Cetinkaya S et al. (2012) Problematic eating behaviour in Turkish children aged 12-72 months: characteristics of mothers and children. Cent Eur J Public Health 20, 257-261.

37. Taylor CM, Wernimont SM, Northstone K et al. (2015) Picky/fussy eating in children: review of definitions, assessment, prevalence and dietary intakes. Appetite 95, 349-359.

38. Xue Y, Lee E, Ning K et al. (2015) Prevalence of picky eating behaviour in Chinese school-age children and associations with anthropometric parameters and intelligence quotient. A cross-sectional study. Appetite 91, 248-255.

39. Kolodziejczyk JK, Merchant G \& Norman GJ (2012) Reliability and validity of child/adolescent food frequency questionnaires that assess foods and/or food groups. J Pediatr Gastroenterol Nutr 55, 4-13.

40. Subar AF, Thompson FE, Smith AF et al. (1995) Improving food frequency questionnaires: a qualitative approach using cognitive interviewing. J Am Diet Assoc 95, 781-788.

41. Thompson FE, Subar AF, Brown CC et al. (2002) Cognitive research enhances accuracy of food frequency questionnaire reports: results of an experimental validation study. J Am Diet Assoc 102, 212-225.

42. Bandini LG, Schoeller DA, Cyr HN et al. (1990) Validity of reported energy intake in obese and nonobese adolescents. Am J Clin Nutr 52, 421-425.

43. Bratteby LE, Sandhagen B, Fan H et al. (1998) Total energy expenditure and physical activity as assessed by the doubly labeled water method in Swedish adolescents in whom energy intake was underestimated by 7 -d diet records. $A m J$ Clin Nutr 67, 905-911.

44. Waling MU \& Larsson CL (2009) Energy intake of Swedish overweight and obese children is underestimated using a diet history interview. J Nutr 139, 522-527. 